\title{
Four years' maternal mortality updates of a high referral burden teaching hospital of Eastern Uttar Pradesh, India
}

\author{
Riden Saxena, Madhu Jain, Anjali Rani*
}

\begin{abstract}
Department of Obstetrics and Gynecology, Institute of Medical Sciences, Banaras Hindu University, Varanasi, Uttar
\end{abstract} Pradesh, India

Received: 18 December 2017

Accepted: 20 January 2018

\section{*Correspondence:}

Dr. Anjali Rani,

E-mail: anjaliraniimsbhu@gmail.com

Copyright: () the author(s), publisher and licensee Medip Academy. This is an open-access article distributed under the terms of the Creative Commons Attribution Non-Commercial License, which permits unrestricted non-commercial use, distribution, and reproduction in any medium, provided the original work is properly cited.

\begin{abstract}
Background: Maternal mortality is still a major challenge in developing countries but in our hospital, it touches the extreme height of MMR. The target of the study is to assess the cause of maternal mortality at Sir Sunder Lal Hospital, Banaras Hindu University, Varanasi, India.

Methods: Data collection was done from the patient maternal mortality records of hospital between 2013 to 2016 . Study comprises only maternal mortality cases. Total 165 maternal deaths were included in this study.

Results: Maternal mortality ratio is extremely high as compare to other studies. In an increasing trend, in the year 2015 MMR was highest. Moreover, we found direct causes accounted $77.5 \%$ of total maternal deaths Hypertensive disorders and eclampsia is the most frequent cause of deaths which represented $33.3 \%$. We found a trend of increased MMR with Increased unbooked cases. $21.2 \%$ of total dead women couldn't get beds in ICU because of not vacancy of beds and $18.8 \%$ of total women died due to non-affordability of ICU expenses.

Conclusions: Our hospital is a high burden referral apex centre of eastern Utter Pradesh in India which experience mostly referred cases from the periphery. PPH and hypertensive disorder are two major causes which lead to deaths. Cardiovascular dysfunction is most accounted for deaths. Mostly patients were needed ventilatory support to survive but lack of separate ICU and improper antenatal visits leads to MMR higher. However, many other factors like illliteracy, poor transportation, poor referral note, poor socio-demographic status should be dealt to incline the MMR.
\end{abstract}

Keywords: Eclampsia, Hypertensive disorders, Maternal mortality

\section{INTRODUCTION}

Pregnancy is one of the most joyful periods of a woman's life while maternal death is an awful and tragic event. Complication during pregnancy and child birth are the major cause of maternal mortality and morbidity among women of reproductive age.

Tenth revision of international classification of disease (ICD-10) defined maternal death as maternal death of a woman while pregnant or within 42 days of termination of pregnancy irrespective of the duration and site of the pregnancy, from any cause related to or aggravated by pregnancy or its management but not from accidental or incidental cause. ${ }^{1}$ Every day approximately 830 women die from preventable cause of pregnancy or child birth related complications globally. Approximately 303000 women deaths were estimated due to pregnancy and obstetrics complications. ${ }^{2}$

According to the World Health Organization (WHO) factsheets, almost $99 \%$ of maternal deaths occurred in developing countries with low recourse settings and most could be prevented. Maternal mortality ratio is declined by only $2.3 \%$ per year between 1990 and 2015. India (17\%) and Nigeria (14\%) both countries account one 
third of all global maternal deaths. UNICEF revealed, annually 55000 women die due to preventable pregnancy and obstetrics related causes in India. ${ }^{3}$

The present study is aimed to determine the trend of MMR over study period and to evaluate the other aspects which relate to the high MMR in our hospital and need of separate ICU consolidated with the labor and delivery suites. The specified objectives of this study is to find out the proportion of women died due to lack of ICU facility, but their lives could be saved if ICU facilities were provided in time, the dead women who were needed to treat in ICU, to determine the frequency of causes of death which could be treated if ICU could be available, to determine the socio demographic status and availability of ICU beds associated with maternal mortality.

\section{METHODS}

This retrospective study was conducted in tertiary care teaching hospital that is one of the highly burden carrying large number of referrals from maternity homes, Primary health centers, community health centres in Eastern Uttar Pradesh. The four years study conducted from 1 January 2013 to 31 December 2016. We included 165 women, who were admitted in Department of Obstetrics and Gynecology and died due to different causes of death while these patients were either antenatal at the time of admission or were within 42 days of their delivery whether they delivered inside or outside our hospital. We excluded late maternal deaths.
Maternal mortality ratio was calculated by dividing the number of maternal deaths by the number of live births during the study period and multiplied by 100,000 .

The maternal death records were retrieved from the departmental record section. Data like reasons for admission, age, parity, reasons of mortality, cause of death, socio-economic status, education, bed vacancy in ICU and affordability of patients for ICU facility were retrieved. We characterized the patients with respect to the need of their ICU admission.

\section{RESULTS}

During the study period, there were total 165 maternal deaths and 102 intrauterine deaths between January 2013 and December 2016.

Table 1: Hospital status during study period.

\begin{tabular}{|lllll|}
\hline $\begin{array}{l}\text { Total maternal } \\
\text { Admissions }\end{array}$ & 2013 & 2014 & 2015 & 2016 \\
\hline Total deliveries & 1991 & 2974 & 2666 & 2675 \\
\hline Total live birth & 1951 & 2020 & 2185 & 2283 \\
\hline Total IUD & 40 & 69 & 85 & 89 \\
\hline Total maternal death & 36 & 33 & 54 & 42 \\
\hline MMR per 100,000 LB & 1845 & 1633 & 2471 & 1839 \\
\hline Mean of MMR & & 2002 & & \\
\hline
\end{tabular}

Table 2: Clinical profile.

\begin{tabular}{|c|c|c|c|c|c|c|}
\hline Profile & & 2013 & 2014 & 2015 & 2016 & Total \\
\hline \multirow{7}{*}{ Age in years } & $<20$ & - & 2 & - & - & 2 \\
\hline & $21-25$ & 19 & 20 & 29 & 28 & $96(58.1 \%)$ \\
\hline & $26-30$ & 11 & 7 & 14 & 9 & $41(24.8 \%)$ \\
\hline & $31-35$ & 3 & 1 & 6 & 4 & $14(8.4 \%)$ \\
\hline & $36-40$ & 2 & 2 & 2 & 1 & 7 \\
\hline & $41-45$ & 1 & 1 & 3 & - & 5 \\
\hline & Mean age in year & 24.6 & 25.3 & 26.8 & 25.5 & 25.5 \\
\hline \multirow{6}{*}{$\begin{array}{l}\text { Gestational age (GA)/status at } \\
\text { admission }\end{array}$} & $<28$ week & 3 & 1 & 9 & 7 & 20 \\
\hline & 28 to 34 weeks & 10 & 4 & 17 & 8 & $39(23.6 \%)$ \\
\hline & 34 to 38 weeks & 12 & 15 & 13 & 13 & $53(32.1 \%)$ \\
\hline & 38 to 40 weeks & 8 & 9 & 10 & 8 & $35(21.2 \%)$ \\
\hline & $>40$ & 3 & 4 & 5 & 6 & 18 \\
\hline & Mean GA in week & 34.4 & 36 & 35.2 & 34.6 & 35.05 \\
\hline \multirow{3}{*}{ Status at death } & Died undelivered & 3 & 2 & 7 & 1 & $13(7.8 \%)$ \\
\hline & Primiparous & 11 & 19 & 15 & 13 & $58(35.1 \%)$ \\
\hline & Multiparous & 22 & 12 & 32 & 28 & $94(56.9 \%)$ \\
\hline \multirow{2}{*}{ ANC registration } & Booked & 4 & 5 & 7 & 9 & $25(15.1 \%)$ \\
\hline & Unbooked & 32 & 28 & 47 & 33 & $140(84.8 \%)$ \\
\hline
\end{tabular}

As the Table 4 shows the epidemiological characteristics of maternal deaths, maximum deaths (58.1\%) were reported in the age of 21 to 25 years and second highest deaths $(24.8 \%)$ were between 25 to 30 years. $56.9 \%$ 
women died with multiparity and $35.1 \%$ with primigravida. Total 13 women died undelivered between the study periods. However, in 2014 maternal mortality was high in primiparous women. Mostly deaths lied in the Gestational age group of 34 to 38 weeks.

Table 3: Socio-demographic profile.

\begin{tabular}{|lllllll|}
\hline Socio-demographic profile & & 2013 & 2014 & 2015 & 2016 & Total \\
\hline Residence & Rural & 19 & 20 & 31 & 24 & $94(56.9 \%)$ \\
\hline & Urban & 6 & 5 & 9 & 5 & $25(15.1 \%)$ \\
\hline & Urban slum & 11 & 8 & 14 & 13 & $46(27.8 \%)$ \\
\hline \multirow{3}{*}{ Economic status (Rs /- per annum) } & Low <100000 & 19 & 18 & 28 & 22 & $87(52.7 \%)$ \\
\cline { 2 - 6 } & Middle (1 to 2 lakh) & 9 & 12 & 17 & 14 & $52(31.5 \%)$ \\
\cline { 2 - 6 } & Upper (>2lakh) & 7 & 3 & 9 & 6 & $25(15.1 \%)$ \\
\hline
\end{tabular}

Table 4: Causes of maternal deaths.

\begin{tabular}{|c|c|c|c|c|c|}
\hline Cause of death in the hospital & $2013(\mathrm{~N}=36)$ & $2014(\mathrm{~N}=33)$ & $2015(\mathrm{~N}=54)$ & $2016(\mathrm{~N}=42)$ & Total $(\mathrm{N}=165)$ \\
\hline Direct cause & & & & & $128(77.5 \%)$ \\
\hline Hypertensive disorders and eclampsia & 11 & 8 & 12 & 9 & $40(24.2 \%)$ \\
\hline Haemorrhage & 7 & 13 & 19 & 16 & $55(33.3 \%)$ \\
\hline Puerperal infection/sepsis & 4 & 3 & 4 & 2 & $13(7.8 \%)$ \\
\hline $\begin{array}{l}\text { Obstructed labor } \\
\text { (including uterine rupture) }\end{array}$ & 2 & 1 & 2 & 2 & $7(4.2 \%)$ \\
\hline Amniotic fluid embolism & 1 & 1 & 2 & - & $4(2.4 \%)$ \\
\hline Abortion related & 1 & 2 & 3 & 2 & $9(5.4 \%)$ \\
\hline \multicolumn{6}{|l|}{ Total } \\
\hline Indirect cause & & & & & $37(22.4 \%)$ \\
\hline Severe anaemia & 3 & 2 & 4 & 3 & $12(7.2 \%)$ \\
\hline Heart disease & 1 & 1 & 2 & 2 & $6(3.6 \%)$ \\
\hline Jaundice & 2 & 1 & 3 & 3 & $9(5.4 \%)$ \\
\hline HIV 1a & 1 & - & - & 1 & $2(1.2 \%)$ \\
\hline Disseminated TB & 1 & - & 1 & 1 & $3(1.8 \%)$ \\
\hline Malignancies (liver secondaries) & 1 & 1 & 2 & 1 & $5(3.0 \%)$ \\
\hline
\end{tabular}

Table 5: Organ dysfunctions required for ICU admission (final cause of ICU admission).

\begin{tabular}{|c|c|c|c|c|c|}
\hline Organ systems & 2013 & 2014 & 2015 & 2016 & Total \\
\hline $\begin{array}{l}\text { Hematological / } \\
\text { thrombocytopenia }\end{array}$ & 6 & 4 & 8 & 4 & 22 \\
\hline Cardiovascular & 8 & 9 & 11 & 8 & 36 \\
\hline Hepatobiliary, GI & 4 & 3 & 4 & 3 & 14 \\
\hline Neurological & 2 & 2 & 5 & 2 & 11 \\
\hline Septicemia & 4 & 2 & 7 & 4 & 17 \\
\hline DIC, coagulation & 2 & 2 & 4 & 4 & 12 \\
\hline Renal & 1 & 2 & 3 & 3 & 9 \\
\hline ARDS, pulmonary & 2 & 1 & 2 & 4 & 9 \\
\hline Embolism & 1 & 2 & 1 & 1 & 5 \\
\hline Metabolic / burns & 1 & 1 & 1 & 2 & 5 \\
\hline $\begin{array}{l}\text { Specific infection } \\
\text { (TB, malaria, } \\
\text { HCV, HBAg, } \\
\text { HEV etc) }\end{array}$ & 2 & 1 & 2 & 2 & 7 \\
\hline $\begin{array}{l}\text { Multi-organ } \\
\text { dysfunction }\end{array}$ & 3 & 4 & 6 & 5 & 18 \\
\hline
\end{tabular}

Most of the maternal deaths were from rural area (56.9\%) and slum urban $(27.8 \%)$ which also associated with the low economic status $(52.7 \%), 70.3 \%$ unbooked patients were reported in the study period. High MMR also reflects the poor community. Due to a high burden referral center $84.8 \%$ of unbooked patients died in this 4 years of period.

Table 6: Treatment needed in ICU.

\begin{tabular}{|lllll|}
\hline $\begin{array}{l}\text { Treatment needed } \\
\text { in ICU }\end{array}$ & \multicolumn{2}{l}{ Number } \\
\hline & $\mathbf{2 0 1 3}$ & $\mathbf{2 0 1 4}$ & $\mathbf{2 0 1 5}$ & $\mathbf{2 0 1 6}$ \\
\hline Ventilatory support & 11 & 15 & 19 & 14 \\
\hline Blood transfusion & 16 & 10 & 13 & 10 \\
\hline $\begin{array}{l}\text { Fresh frozen plasma } \\
\text { transfusion }\end{array}$ & 3 & 6 & 8 & 5 \\
\hline Dialysis & 2 & 3 & 5 & 6 \\
\hline Platelets transfusion & 1 & 2 & 8 & 5 \\
\hline Surgical intervention & 13 & 8 & 14 & 12 \\
\hline
\end{tabular}


When we analyzed the leading cause of death in four-year period direct cause accounted $77.5 \%$ of deaths. Hypertensive disorders and eclampsia (33.3\%) was convicted highest and Obstetrics hemorrhage (24.2\%) were at second position while Indirect cause are reported $22.4 \%$ and severe anemia accounted highest for maternal death $(7.2 \%)$. Cardio-vascular system dysfunction was the most common organ dysfunctions which lead to the maternal mortality. Among 165 women ventilator support, blood transfusion and surgical intervention were required most in the intensive care unit (ICU) to save the life but only $53.9 \%$ women could get ICU admission, $21.2 \%$ could not get ICU facility due to unavailability of vacant beds although $6.6 \%$ women's family refused to take ICU due to other reasons and $18.8 \%$ of died women's family couldn't afford the ICU.

Table 7: ICU admission profile.

\begin{tabular}{|ll|llll|}
\hline Year & $\begin{array}{l}\text { Bed not vacant } \\
\text { in ICU }\end{array}$ & Not affordable & Admissions in ICU & Refusal and other reason Total \\
\hline 2013 & 7 & 5 & 21 & 3 & 36 \\
\hline 2014 & 9 & 7 & 15 & 2 & 33 \\
\hline 2015 & 11 & 9 & 29 & 5 & 54 \\
\hline 2016 & 8 & 9 & 24 & 1 & 42 \\
\hline Total mortality & 35 & 30 & 89 & 6.6 & 165 \\
\hline Percentage (\%) & 21.2 & 18.8 & 53.9 & & 16 \\
\hline
\end{tabular}

\section{DISCUSSION}

The maternal mortality rate (MMR) in developed countries in 2015 was 12 per 100000 live births whereas developing countries account 240 per 100000 live births which is a vast difference of $15 \%$ higher than developed countries. Almost all maternal deaths occurred in developing countries. High numbers of maternal mortality reflect the need of more development in health care services and management. With a high MMR India accounts one third of total maternal deaths of the world. MMR depends on many factors including socioeconomic status, literacy rate, and availability of health care facilities. ${ }^{4}$

Most maternal deaths are preventable as the health care solutions or complication management facilities are well known. Pregnancy and child birth can be the most complicated situation for women which can lead to death. Such situation can be overcome in critical care unit if provide timely. Critical care practitioners have thorough knowledge and equipments to control the complication arise due to pregnancy and child birth. ${ }^{5}$ This study was done to review the aspects of maternal deaths and need to save the women's lives.

In 4 years of study period we calculated mean MMR 2002 per 100000 live births as it is an intensified MMR. Same study done in our hospital by Jain $M$ et al calculated 2269 mean MMR. ${ }^{6}$ Our hospital is a tertiary referral teaching hospital which caters to all high risk and complicated cases from different parts of eastern Utter Pradesh, vast area of western part of Bihar state and border areas of Madhya Pradesh state. Although accurate MMR calculation is difficult to access, and any hospital cannot be a true representative of that area. ${ }^{6}$
Majority of women were from age group of 21 to 25 $(58.1 \%)$. Dasari P et al also found comparable result of major mortality in the 21 to 25-year age group and multiparous women as the present study. Most women died in 34 to 38 weeks gestational age $(32.5 \%)$ same as Dasari P study. ${ }^{4}$ In the present study hemorrhage headed the direct cause list with $33.3 \%$ as observed in Ramachandra PM et al. ${ }^{7}$ Jain $M$ et al found relevancy with us in ANC registration status. ${ }^{6}$ Most of the causes are preventable. $33.3 \%$ of total deaths due to hemorrhage associated with co-morbidity like anemia. Delay in recognition of $\mathrm{PPH}$, treatment, referral like factors were analyzed in major of cases.

Total 7 cases were registered of inter uterine rupture. 9 deaths attributed to abortion related complications and 4 cases to amniotic embolism. Significant numbers of deaths were associated with organ dysfunctions. Cardiovascular dysfunctions (36 cases) were most common in study period. Mostly death causes were associated with the need of ventilator support, blood transfusion, platelets and frozen plasma transfusion and dialysis. Many cases were required surgical interventions. Various researchers supported similar therapeutic measures that could save the lives. ${ }^{8-11}$

Extremely high MMR was associated with the illiteracy, rural, slum, low economic status families which is emphasize the relation of death with that low socioeconomic women. $18.8 \%$ of women could not afford the ICU facility, $21.2 \%$ of total women died due to not availability of beds in ICU, only $53.9 \%$ of total died women could get bed in ICU.

There is lack of separate ICU for obstetrics patients in our Hospital. According to the Irene YV antenatal care 
present at the periphery can prevent the women from majority of complications and deaths related to the obstetrics and pregnancy. ${ }^{12}$ Critically ill condition can be result in to death so early referral to tertiary care center coupled with ICU should be an approach to reduce the MMR. Proper implementation of National Rural Health Mission (NRHM) scheme can play a vital role in saving of many mothers' lives.

\section{CONCLUSION}

Maternal mortality rate corresponds the value of women life. Extremely high mortality has many factors including socio economic factor and low resources in health care facilities. Our region accounts a huge deprived population and our hospital is a high referral centre established in low setting population which is required multidisciplinary approach about cheaper and high quality of health care facilities. In the present study mostly, women were required ICU facilities, but half of the women could not get ICU facilities. Inclusion of low cost and separate intensive care unit associated to labour and obstetrics suits is essential to achieve goal of reduced MMR. However, many other factors like ill-literacy, poor transportation, poor referral note, poor sociodemographic status should be dealt to incline the MMR.

Funding: No funding sources Conflict of interest: None declared

Ethical approval: The study was approved by the Institutional Ethics Committee

\section{REFERENCES}

1. World health organization. ICD-10: International statistical classification of diseases and related health problems. Geneva. World Health Organization. 1992.

2. Trend in maternal mortality 1990 to 2013 . Estimates by WHO, UNICEF, UNFPA, The World Bank and the United Nations Population Division. WHO.
2014. Available at http://apps.who.int/iris/bitstream/10665/112682/2/97 89241507226_eng.pdf?ua=1

3. UNICEF. Maternal health in focus. UNICEF India. available at http://unicef.in/Whatwedo/1/MaternalHealth

4. Dasari P. Maternal mortality and its relationship to emergency obstetric care (EmOC) in a tertiary care hospital in South India. Obstet Med. 2015;8(2):8691.

5. Naylor DF, Olson MM. Critical care obstetrics and gynecology. Crit Care Clin. 2003;19:127-49.

6. Jain M, Maharahaje S. Maternal mortality: a retrospective analysis of ten years in a tertiary hospital. Indian J Prev Soc Med. 2003;34:103-11.

7. Ramachandra PM, Manohar R. A five-year study of maternal mortality in Mandya district, Karnataka, India. IJRCOG. 2017;5(5):1585-8.

8. Diaz de Leon PM, Briones GJC, Kably AA, Vallejo BJ, Morales E, Aragón JG. Intensive care in obstetrics. Rev Asoc Mex Crity Ter Int. 1997;11:3640.

9. Dalal N, Patkar V, Karnik N. Critical care in obstetrics. Bombay Hosp J. 1999;41:512-6.

10. Sheela CN, Mhaskar A, Mhaskar R. Critical care in obstetrics: a 3-year review in a tertiary referral hospital. Hypertension. 2004;6:20.

11. Anwari JS, Butt AA, Al-Dar MA. Obstetric admissions to the intensive care unit. Saudi Med J. 2004;25:1394-9.

12. Irene YV, Vaneet K, Gurvinder K, Arun A, Lalita A. Critical care in obstetrics-scenario in a developing country. J Obstet Gynecol India. 2008;58(3):217-0.

Cite this article as: Saxena R, Jain M, Rani A. Four years' maternal mortality updates of a high referral burden teaching hospital of Eastern Uttar Pradesh, India. Int J Reprod Contracept Obstet Gynecol 2018;7:927-31. 